\title{
ANALISA PERUBAHAN POLA HIDROLOGI DI DAERAH MUARA KALI PORONG PASCA PERISTIWA LAPINDO DENGAN CITRA SATELIT SPOT 4 DAN ALOS
}

\author{
Mochamad Machfud, Agung Budi Cahyono \\ Program Studi Teknik Geomatika FTSP-ITS, Kampus ITS Sukolilo, Surabaya, 60111 \\ Email : machfud.danuh@gmail.com, agungbcahyo@yahoo.com
}

\begin{abstract}
Abstrak
Pesisir merupakan salah satu tempat untuk muara sungai dimana hilir dari suatu sungai itu berakhir sebelum menuju lepas laut. Di kabupaten Sidoarjo tedapat kali yaitu Kali Porong yang merupakan ujung dari sungai Brantas yang semenjak tahun 2006 digunakan sebagai tempat untuk mengalirkan lumpur Lapindo ke laut. Hal ini menyebabkan perubahan dari ekologi dari Kali Porong. Salah satunya adalah mengganggu pola hidrologi yang ada di Kali Porong. Oleh karena itu diperlukan analisa untuk penentuan pola hidrologi secara multitemporal setelah Kali Porong digunakan sebagai tempat mengalirkannya lumpur untuk menuju laut timur Jawa yang dimana akan mempercepat terbentuk sedimentasi yang dapat menggagu pola hidrologi Kali Porong.
\end{abstract}

Pengamatan dilakukan dengan metode penginderaan jauh dengan menganalisa citra ALOS dan SPOT 4 dari tahun 2010 sampai 2011. Klasifikasi yang digunakan dalam analisa ini adalah klasifikasi Terselia atau klasifikasi beracuan yang menggunakan Maximum Likehood Standard dan menganalisa DEM SRTM dengan menggunakan menu spatial analyst tools untuk menentukan arah aliran sungai (flow direction) dan akumulasi aliran sungai (flow accumulation).

Hasil dari penelitian ini memperlihatkan bahwa dalam peta aliran sungai terlihat gradasi warna dari biru tua menuju ke biru muda menjelaskan bahwa arah aliran sungai yang menunjukan semakin besar akumulasi pencampuran antara air sungai dengan lumpur dititik tersebut. Daerah pesisir Sidoarjo lebih di dominasi oleh pola aliran sungai dendritik. Pola aliran sungai daerah muara Kali Porong relatif tetap.

Kata Kunci : Hidrologi, Citra SPOT 4, Citra ALOS

\section{PENDAHULUAN}

\section{Latar Belakang}

Wilayah pesisir didefinisikan sebagai wilayah peralihan antara laut dan daratan, kearah darat mencakup daerah yang masih terkena pengaruh percikan air laut atau pasang surut, dan ke arah laut mencakup daerah yang penuh dengan air. Pada daerah ini termasuk ke dalam daerah lahan basah. Lahan basah merupakan istilah kolektif tentang ekosistem yang pembentukan nya dikuasai air, dan proses serta cirinya terutama dikendalikan air. Suatu lahan basah adalah suatu tempat yang cukup basah selama waktu cukup panjang bagi pengembangannya. Lahan basah didefinisikan berdasarkan tiga parameter, yaitu hidrologi, vegetasi hidrofitik, dan tanah hidrik (Cassel, 1997).

Daerah Kali Porong Sidoarjo merupakan daerah kawasan pesisir utara Jawa Timur yang berbatasan dengan laut. Kali Porong ini merupakan percabangan dari sungai Brantas yang memiliki panjang sekitar $320 \mathrm{~km}$. Karena permasalahan luapan lumpur Lapindo, semenjak tahun 2006 aliran sungai ini dipergunakan untuk menggelontorkan sebagian semburan lumpur ke Selat Madura. Sebagian lumpur ini dipompa masuk ke salah satu anak sungai di hilir, yakni Kali Porong yang dapat menyebabkan pendangkalan pada Kali Porong itu sendiri karena terbentuk endapan dari lumpur yang di alirkan ke Kali Porong. Karena hal tersebut maka menyebabkan terganggunya siklus hidrologi dari Kali Porong itu sendiri (Arisandi, P. 2008).

Oleh karena itu, perlu adanya suatu penelitian mengenai analisa pola hidrologi daerah Kali Porong dengan menggunakan teknologi penginderaan jauh secara multitemporal tahun 2010 - 2011 untuk mendapatkan data peta lahan basah untuk mengetahui perubahan pola hidrologi pada tiap tahun dengan data utama citra satelit SPOT 4 dan ALOS. 


\section{Batasan Masalah}

Dalam penelitian ini permasalahan yang dimunculkan adalah bagaimana memperoleh informasi dari citra satelit SPOT 4 dan ALOS serta data pendukung lainya sehingga dapat dimanfaatkan untuk mengetahui tutupan lahan, luasan dan pola aliran sungai yang digunakan untuk menganalisa perubahan pola hidrologi di daerah muara Kali Porong pasca peristiwa Lapindo?

\section{Tujuan Penelitian}

Tujuan penelitian ini adalah :

Melakukan pengolahan dan analisis data dari citra satelit SPOT 4 dan ALOS sehingga mendapatkan peta tutupan lahan.

Melakukan pengolahan data DEM SRTM untuk mendapatkan peta hidrologi.

Mengetahui pengaruh peristiwa Lapindo terhadap pola aliran hidrologi di daerah Kali Porong

\section{METODOLOGI PENELITIAN}

\section{Lokasi Penelitian}

Lokasi penelitian Tugas Akhir ini dilakukan pada daerah muara Kali Porong Sidoarjo yang terletak antara $7^{0} 10^{\prime} 20^{\prime \prime}$ LS $-7^{0} 36^{\prime} 00^{\prime \prime}$ LS dan $112^{0} 34^{\prime} 52^{\prime \prime}$ BT $-112^{\circ} 54^{\prime} 36^{\prime \prime}$ BT

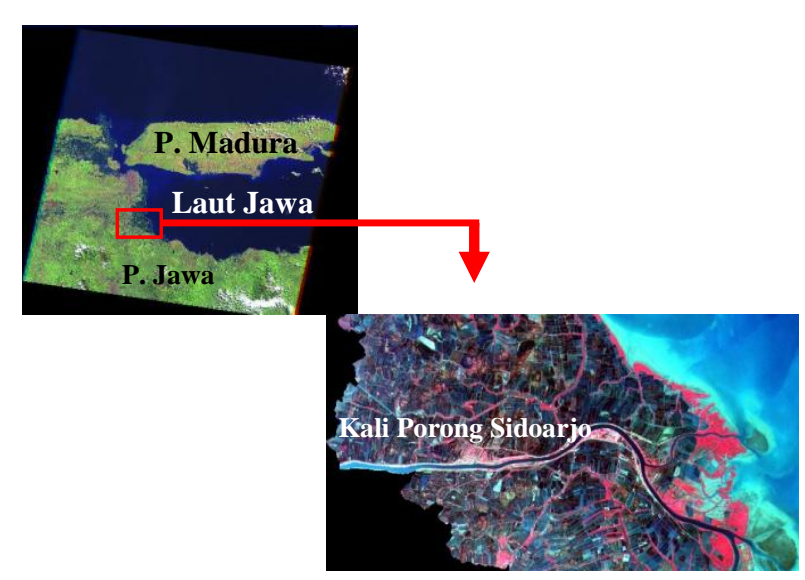

Gambar 1. Lokasi Penelitian

\section{Data Dan Peralatan}

\section{- Data}

Data yang digunakan dalam penelitian ini adalah:

1. Citra satelit ALOS akuisisi 1 September 2010

2. Citra satelit SPOT 4 akuisisi 21 Juli 2011
3. Citra Landsat 7 ETM Orthometrik akuisisi tanggal 17 Agustus 2000 sebagai acuan koreksi geometrik.

4. Data SRTM / Shuttle Radar Topographic Mission (Sumber BAKOSURTANAL).

\section{- Peralatan}

Peralatan yang digunakan dalam penelitian ini adalah:

1. Perangkat Keras (Hardware)

a. Notebook DELL Intel ${ }^{\circledR}$ Core $^{\mathrm{TM}} 2{ }^{\circledR}$, memori $514 \mathrm{MB},(1,87 \mathrm{GHz})$, Hard Disk $80 \mathrm{~Gb}$

b. GPS Hendheld

2. Perangkat Lunak (Software)
a. ENVI 4.6.1 untuk pengolahan citra.
b. Matlab 7.0 untuk perhitungan Strength of Figure
c. ArCGIS 9.3 untuk pembuatan peta hidrologi.

\section{Diagram Alir Pengolahan Data}

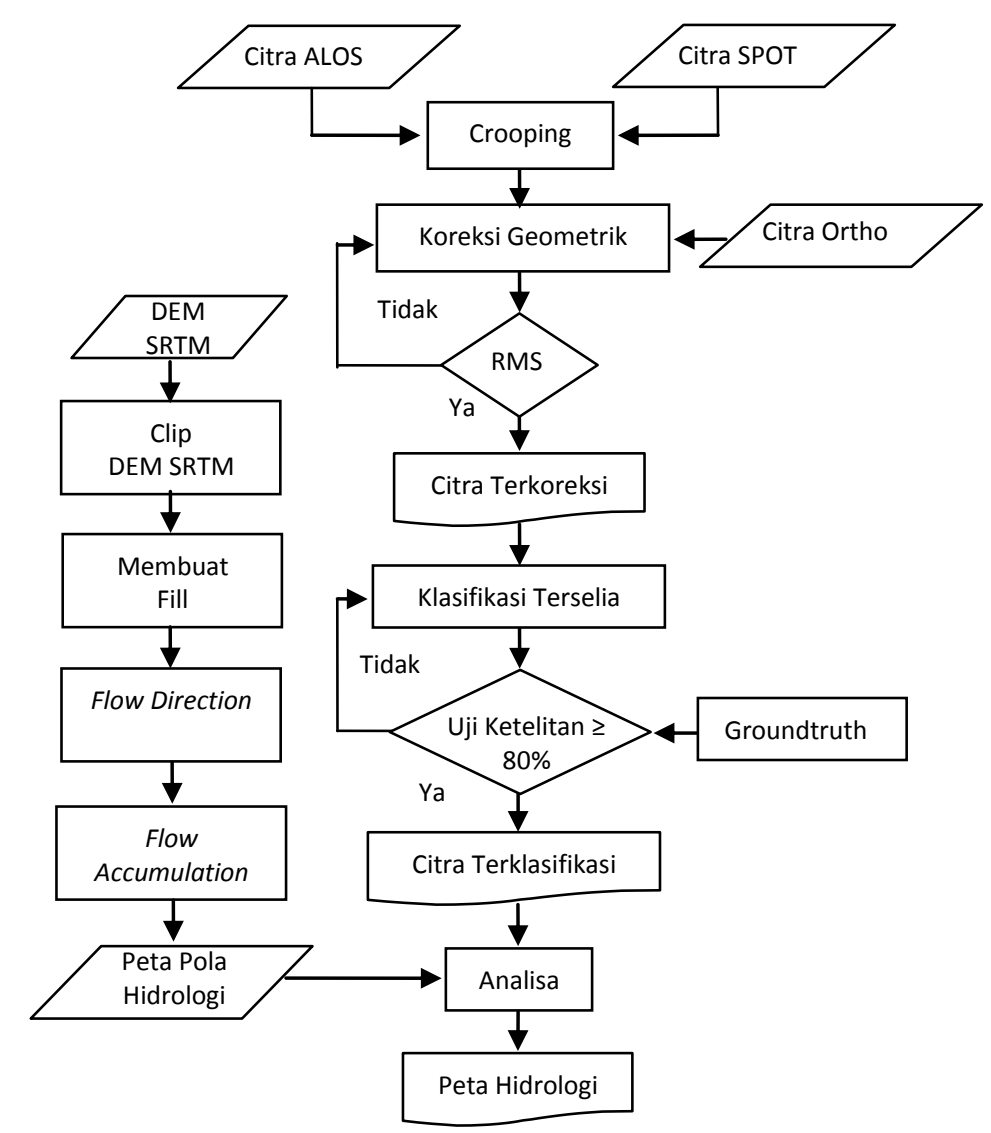

Gambar 2. Diagram Tahap Pengolahan Data 
Penjelasan dari diagram alir penelitian diatas adalah :

1. Pengumpulan data untuk penelitian yaitu Citra ALOS tahun 2010, Citra SPOT 4 tahun 2011 dan data SRTM.

2. Pra Pengolahan Data

\section{a. Cropping}

Crooping adalah pemotongan citra yang dilakukan pada area penelitian agar fokus terhadap area penelitian dan pemrosesan data lebih efektif.

b. Koreksi Geometrik

Koreksi geometrik adalah koreksi yang dilakukan untuk mereduksi terjadinya distorsi geometrik pada citra. Hal tersebut dilakukan dengan cara mencari hubungan antara sistem koordinat citra dengan sistem koordinat geografis (sistem koordinat tanah) menggunakan Ground Control Point (GCP). Koreksi geometrik yang dilakukan menggun akan referensi citra Landsat ortho 2000. Hasil atau nilai dari koreksi geometrik diwakili oleh nilai RMS error dari perhitungan GCP.

3. Pengolahan Data

\section{a. Citra Terkoreksi}

Citra terkoreksi yaitu melakukan koreksi citra yang memiliki nilai Root Mean Square error harus kurang atau sama dengan satu pixel (RMS $\leq 1$ pixel).

b. Klasifikasi Terselia

Dalam penelitian ini digunakan klasifikasi terselia atau klasifikasi beracuan. Klasifikasi terselia adalah klasifikasi meliputi sekumpulan algoritma yang didasari pemasukan contoh obyek (berupa nilai spektral) oleh operator. Classification type yang digunakan adalah Maximum Likehood Standard. Tipe klasifikasi ini dipilih karena mampu menampilkan hasil klasifikasi yang sesuai dengan warna training area yang telah dilakukan.

c. Groundtruth

Groundtruth merupakan pengambilan data koordinat untuk pengecekan di lapangan. Dalam groundtruth dilakukan pengambilan beberapa titik (sample area) yang dipilih dari setiap penggunaan lahan / tutupan lahan.

d. Uji Ketelitian
Uji ketelitian merupakan pengecekan dari data lapangan dengan citra yang telah terklasifikasi yaitu dengan mengambil titik training sample pada kerangka jaring yang telah dibuat dengan melakukan grountruth pada lokasi - lokasi yang telah ditentukan. Kecocokan data tersebut bernilai $\geq 80 \%$.

e. DEM SRTM

Data DEM sebelumnya perlu dilakukan pemotongan (crooping) sesuai area penelitian. Selanjutnya dilakukan analisa hidrologi dari DEM tersebut mengguna kan menu spatial analyst tools pada software ArcGis 9.3. Data DEM tersebut dianalisis untuk menentukan arah aliran sungai (flow direction) dan akumulasi aliran sungai (flow accumulation).

f. Analisis

Pada tahap ini dianalisa pola perubahan hidrologi yang terjadi di daerah penelitian akibat pembuangan lumpur Lapindo ke Kali Porong Sidoarjo.

4. Pembuatan Peta Hidrologi

Setelah proses analisa dilakukan maka data yang telah diperoleh di buat peta pola hidrologi muara Kali Porong dari tahun 2010 sampai 2011.

\section{HASIL DAN PEMBAHASAN}

\section{Koreksi Geometrik Citra dan Nilai SOF}

Hasil koreksi geometrik pada Citra ALOS dan Citra SPOT 4, sebagai berikut:

- Untuk citra ALOS tahun 2010 memiliki nilai $\mathrm{RMS}_{\text {error }}$ sebesar 0.872944

- Untuk citra SPOT 4 tahun 2011 memiliki nilai $\mathrm{RMS}_{\text {error }}$ sebesar 0.908768

Sedangkan untuk nilai SOF (strength of figure) pada Citra ALOS dan Citra SPOT 4, sebagai berikut:

- Untuk citra ALOS tahun 2010 memiliki nilai SOF sebesar 0.0015

- Untuk citra SPOT 4 tahun 2011 memiliki nilai SOF sebesar 0.0012

\section{Klasifikasi Citra}

Klasifikasi yang dilakukan pada citra ALOS tahun citra ALOS tahun 2010 menggunakan klasifikasi tersilia. Hasil dari klasifikasi citra ALOS tahun 2010 yaitu berupa Peta tutupan lahan yang diklasifikasi menjadi 5 kelas yaitu: 
Tabel 1. Jenis dan luas area tutupan lahan pada daerah Kali Porong Sidoarjo Tahun 2010

\begin{tabular}{cccc}
\hline No & $\begin{array}{c}\text { Jenis Tutupan } \\
\text { Lahan }\end{array}$ & Luas Area (Ha) & $\begin{array}{c}\text { Luas Area } \\
\text { (\%) }\end{array}$ \\
\hline 1 & Sungai & 273,16 & 2,38 \\
2 & Tambak & 6906,98 & 60,34 \\
3 & Vegetasi & 1488,67 & 13,00 \\
4 & Laut & 1199,93 & 10,48 \\
5 & Endapan & 1576,17 & 13,77 \\
\hline
\end{tabular}

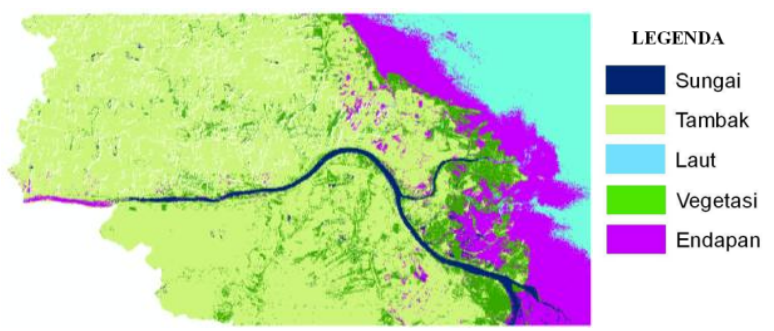

Gambar 3. Hasil Klasifikasi Tutupan Lahan Kali Porong Sidoarjo 2010

Sedangkan untuk klasifikasi yang dilakukan pada citra SPOT 4 menggunakan klasifikasi tersilia. Hasil dari klasifikasi SPOT 4 yaitu berupa Peta tutupan lahan yang diklasifikasi menjadi 5 kelas yaitu:

Tabel 2. Jenis dan luas area tutupan lahan pada daerah Kali Porong Sidoarjo Tahun 2011

\begin{tabular}{cccc}
\hline No & $\begin{array}{c}\text { Jenis Tutupan } \\
\text { Lahan }\end{array}$ & Luas Area (Ha) & $\begin{array}{c}\text { Luas Area } \\
\text { (\%) }\end{array}$ \\
\hline 1 & Sungai & 349,12 & 3,01 \\
2 & Tambak & 7342,61 & 63,39 \\
3 & Vegetasi & 1866,81 & 16,11 \\
4 & Laut & 996,72 & 6,60 \\
5 & Endapan & 1027,58 & 8,87 \\
\hline
\end{tabular}

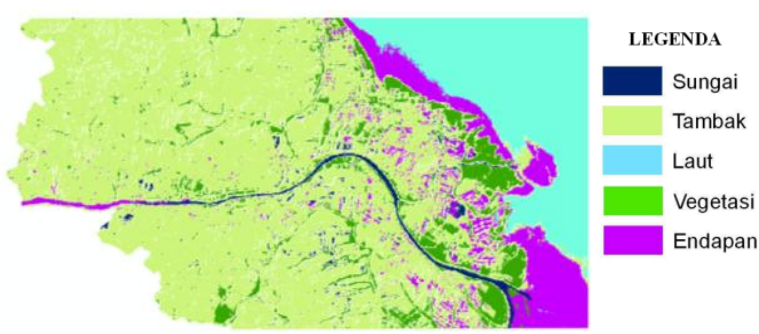

Gambar 4. Hasil Klasifikasi Tutupan Lahan Muara Kali Porong Sidoarjo 2011

Dari hasil pengolahan 2 tahun di atas, tutupan lahan terbesar di dominasi oleh tambak. Dan dari hasil klasifikasi tersebut juga dapat dilihat terjadinya sedimentasi didaerah daerah muara dan pesisir Kali Porong. Hal ini menunjukan bahwa didaerah tersebut cukup besar terjadinya sedimentasi.

\section{Uji Klasifikasi}

Uji klasifikasi dilakukan untuk mengetahui ketelitian hasil klasifikasi dengan keadaan sebenarnya dilapangan. Uji klasifikasi dilakukan dengan cara membandingkan sample titik-titik koordinat dilapangan yang sesuai dengan kelas tutupan lahan dengan hasil klasifikasi citra yang telah dilakukan. Uji Ketelitian tersebut di lakukan pada citra dengan menggunakan rumus :

$$
\begin{array}{lll} 
& K l=\frac{J K l}{J S l} \times 100 \% \\
\text { Ket : } \quad \mathrm{KI} \quad: \text { Ketepatan Interpretasi } \\
\quad \mathrm{JKI} \quad: \text { Jumlah Kebenaran Interpreatsi } \\
\mathrm{JSL} \quad: \text { Jumlah Sampel Lapangan }
\end{array}
$$

Dari hasil Groundtruth yang telah dilakukan, maka :

$$
\begin{aligned}
& \mathrm{JSL}=35 \text { titik } \\
& \mathrm{JKI}=35-6=29 \text { titik } \\
& K l=\frac{29}{35} \times 100 \% \\
& K I=82,85 \%
\end{aligned}
$$

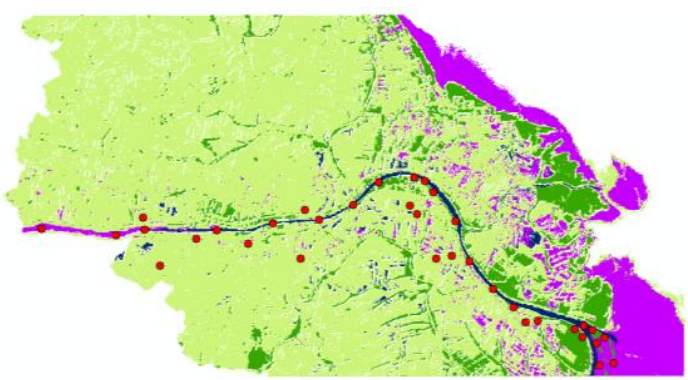

Gambar 5. Lokasi Titik Groundtruth

\section{Pengolahan Data SRTM}

Data DEM yang sebelumnya telah dilakukan pemotongan (crooping) sesuai area penelitian selanjutnya dilakukan analisa hidrologi dari DEM tersebut untuk menentukan arah aliran sungai (flow direction) dan akumulasi aliran sungai (flow accumulation).

Dari analisa data DEM SRTM memperlihatkan aliran sungai terjadi gradasi warna dari biru tua menuju ke biru muda menjelaskan bahwa arah aliran sungai yang menunjukan semakin besar akumulasi pencampuran antara air sungai dengan lumpur dititik tersebut 


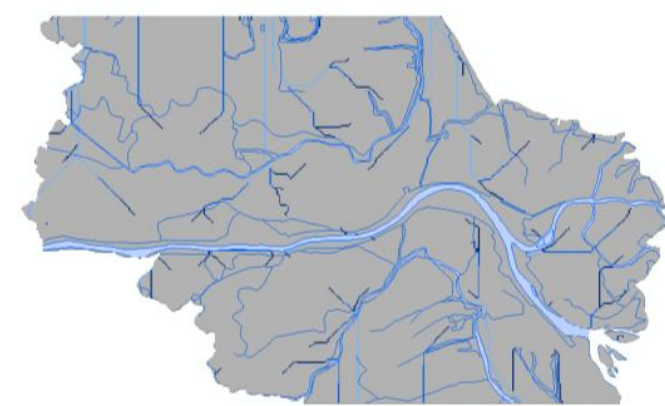

Gambar 6. Analisa Hidrologi Daerah Muara Kali Porong

\section{Pola Aliran Sungai}

Daerah pesisir Sidoarjo lebih di dominasi oleh pola aliran sungai Dendritik yaitu seperti percabangan pohon, percabangan tidak teratur dengan arah dan sudut yang beragam.

Pola aliran sungai pada tahun 2010 dan 2011 relatif tetap. Berdasarkan asal airnya sungai pada pesisir Sidoarjo tergolong sungai hujan yaitu sungai yang airnya berasal dari air hujan atau sumber mata air dan daerah alirannya ditutupi oleh vegetasi.

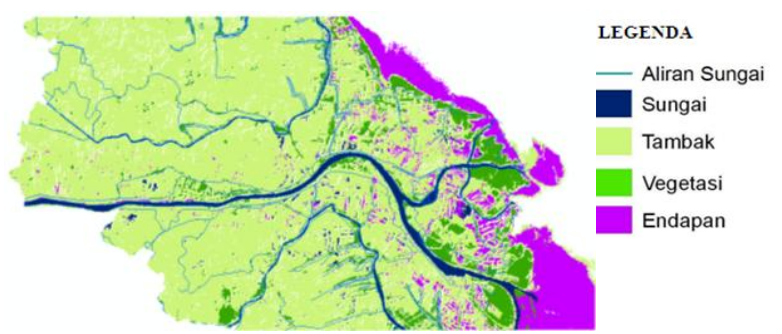

Gambar7. Pola Aliran Sungai pesisir Sidoarjo

\section{Muara Kali Porong}

Pada bagian muara kali Porong terdapat pengaruh akibat pembuangan lumpur Lapindo ke kali Porong. Pada tahun 2010 akibat pembuangan lumpur ke kali Porong mengakibatkan terbentuknya endapan atau sedimentasi di bagian muara kali porong seluas $2125861.31 \mathrm{~m}^{2}$ namun berangsur-angsur berkurang pada tahun 2011 menjadi $943428.37 \mathrm{~m}^{2}$

Tabel 3. Jenis dan luas area tutupan lahan pada daerah Kali Porong Sidoarjo Tahun 2010

\begin{tabular}{cccc}
\hline No & $\begin{array}{c}\text { Jenis Tutupan } \\
\text { Lahan }\end{array}$ & Luas Area $\left(\mathbf{m}^{2}\right)$ & $\begin{array}{c}\text { Luas Area } \\
(\%)\end{array}$ \\
\hline 1 & Tambak & 1653131.81 & 22,44 \\
2 & Vegetasi & 3584662.31 & 48,68 \\
3 & Endapan & 2125861.31 & 28,86 \\
\hline
\end{tabular}

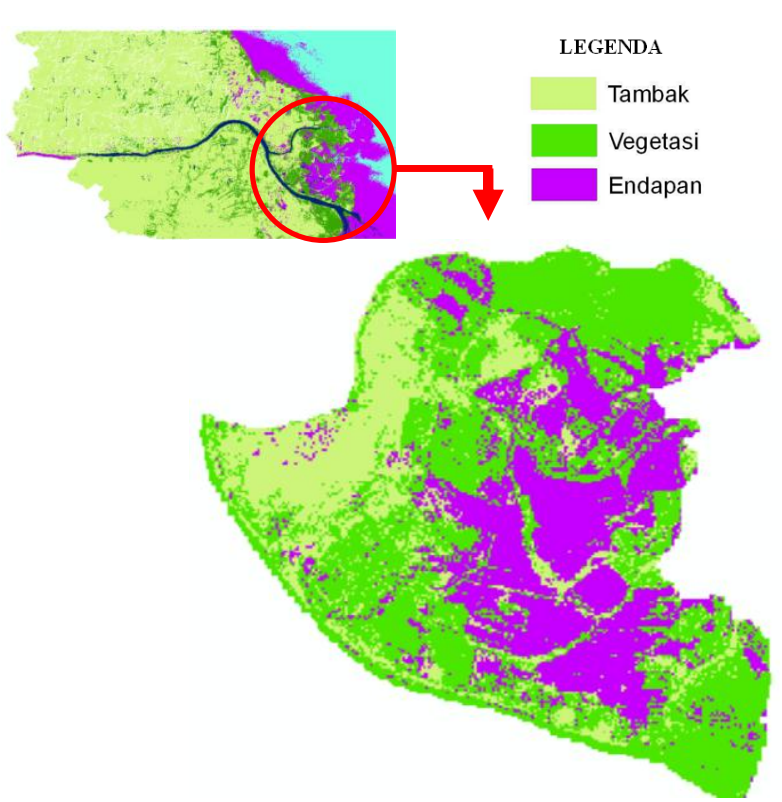

Gambar 8. Endapan di Muara Kali Porong Tahun 2010

Tabel 4. Jenis dan luas area tutupan lahan pada daerah Kali Porong Sidoarjo Tahun 2011

\begin{tabular}{cccc}
\hline No & $\begin{array}{c}\text { Jenis Tutupan } \\
\text { Lahan }\end{array}$ & Luas Area $\left(\mathbf{m}^{\mathbf{2}}\right)$ & $\begin{array}{c}\text { Luas Area } \\
\mathbf{( \% )}\end{array}$ \\
\hline 1 & Tambak & 3785644.33 & 51,73 \\
2 & Vegetasi & 2588437.68 & 35,37 \\
3 & Endapan & 943428.37 & 12,89 \\
\hline
\end{tabular}
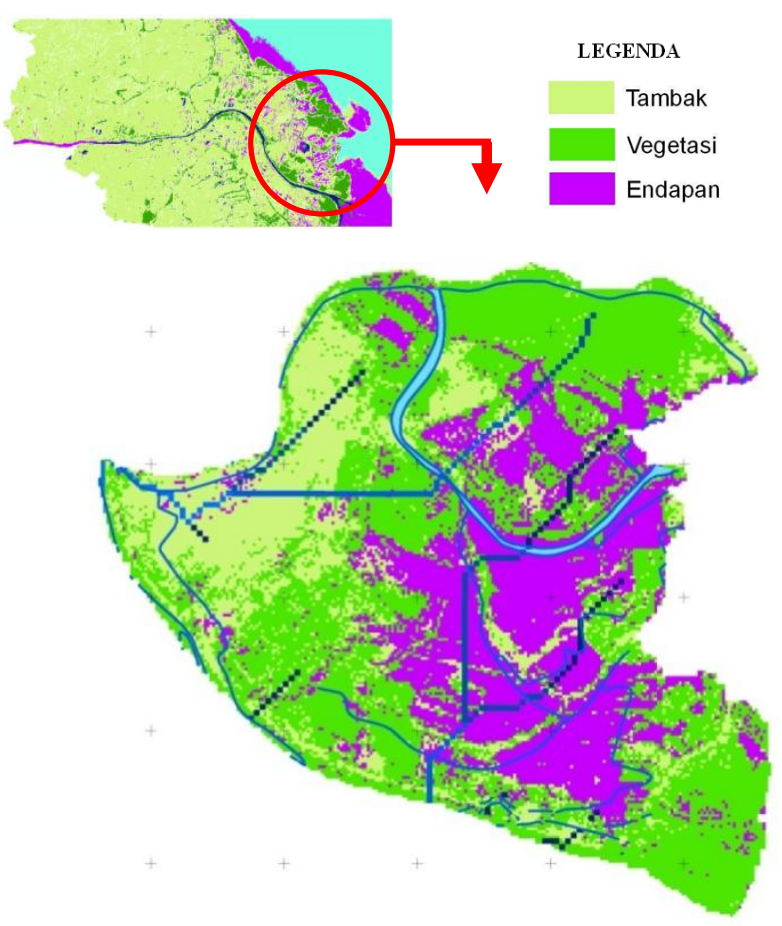

Gambar 9. Endapan di Muara Kali Porong Tahun 2011 
Endapan lumpur yang terbentuk dimuara kali porong sedikit banyak menimbulkan pengaruh terhadap hidrologi muara tersebut karena endapan tersebut menutupi aliran sungai - sungai kecil yang ada sebelumnya.

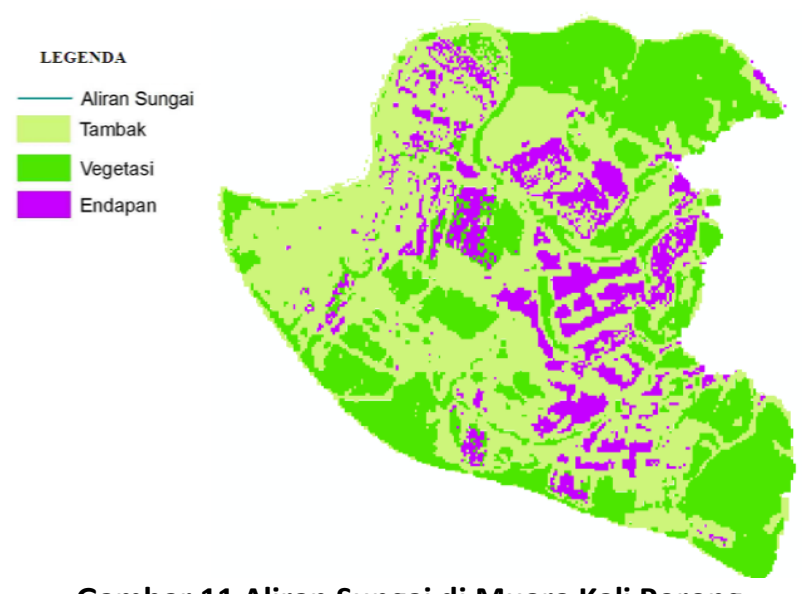

Gambar 11 Aliran Sungai di Muara Kali Porong

\section{KESIMPULAN DAN SARAN}

\section{Kesimpulan}

Berdasarkan analisa perubahan pola hidrologi di daerah muara Kali Porong pasca peristiwa Lapindo dengan citra satelit ALOS dan SPOT 4 tahun 2010 sampai dengan 2011 dapat disimpulkan sebagai berikut:

1. Hasil dari proses klasifikasi tutupan lahan dengan metode Maximum Likehood Standard di dominasi oleh kelas tambak yang mencapai $63,39 \%(7342,61 \mathrm{Ha})$.

2. Dalam peta aliran sungai terlihat bahwa gradasi warna dari biru tua menuju ke biru muda menjelaskan bahwa arah aliran sungai yang menunjukan semakin besar akumulasi pencampuran antara air sungai dengan lumpur titik tersebut.

3. Daerah pesisir Sidoarjo lebih di dominasi oleh pola aliran sungai Dendritik. Pola aliran sungai daerah muara Kali Porong relatif tetap.

4. Pembuangan lumpur ke kali Porong mengakibatkan terbentuknya endapan di bagian muara kali Porong seluas 2125861,31 $\mathrm{m}^{2}$ pada tahun 2010, namun berangsur-angsur berkurang pada tahun 2011 menjadi $943428,37 \mathrm{~m}^{2}$

5. Dari hasil di atas di dapat bahwa pembuangan lumpur ke Kali Porong mengakibatkan terjadinya endapan di muara Kali Porong.

\section{Saran}

Adapun saran yang dapat disampaikan pada penelitian ini adalah :

1. Dalam penelitian yang lebih lanjut disarankan agar dalam penentuan arah aliran sungai beserta pola hidrologinya apakah akan mengalami pendangkalan, penyempitan atau pelebaran sungai akibat dari pembuangan lumpur tersebut.

2. Analisa hidrologi sebaiknya dapat menggunakan DEM SRTM atau peta kontur yang beresolusi lebih tinggi agar dapat menghasilkan data yang lebih akurat..

\section{DAFTAR PUSTAKA}

Abidin, H.Z., dkk. 2002. Survei Dengan GPS. Jakarta : Pradnya Paramitha.

Arisandi, P. 2008. Bencana Baru Di Kali Porong.Gajah Mada University

Ardi, L. 2011, Analisa Hidrologi Dan Daerah Genangan Di Pantai Surabaya-Sidoarjo Pasca Pembangunan Jembatan Suramadu Dan Peristiwa Lapindo Dengan Citra SPOT 4

Cassel, D.K. 1997. Foreword. Dalam: M.J. Vepraskas \& S.W. Sprecher (eds.), Aquic

Conditions and Hydric Soils: The Problem Soils. SSSA Special Publication Number 50 . h vii.

Ekadinata,dkk. 2008. Sistem Informasi Geografis dan Penginderaan Jauh Untuk Pengelolaan Bentang Lahan Berbasis Sumber Daya Alam. World Agroforestry center - bogor

Hapsari, H. 2007. Hitung Kerangka Geodesi. Tekni Geomatika ITS -Surabaya

Harlick. R.M., K. Sharmugam, I. Dinstein. 1973. Tectural features for image classification.

Jaelani, LM. 2011. 1_Principles_of_Remote_Sensing. Geomatics Eng. Dept. ITS -Surabaya

Lillesand, K. 1994. Penginderaan jauh dan Interpretasi Citra, Gajah Mada University Press.

Maeda, K. and K, TODA. 2005. Data Compression and Data Relay for Transmission of ALOS Data, JAXA.

Maryantika, N. 2011. Analisa Perubahan Vegetasi Ditinjau Dari Tingkat Ketinggian Dan Kemiringan Lahan Menggunakan Citra Satelit Landsat Dan SPOT 4 (Studi Kasus Kabupaten Pasuruan). Surabaya : Teknik Geomatika ITS.

Prima,W. 2008. Metode Interpretasi Dan Klasifikasi Penggunaan Lahan. Surabaya.

Purwadhi, S.H. 2001. Interpretasi Citra Digital. Jakarta: Grasindo. 
Rahmah. 2009, penentuan daerah retensi banjir mengunaka teknologi penginderaan jauh dan sistem informasi geografi di Mojokerto. Program studi Teknik Geomatika ITS. Surabaya

Siddik, A. 2008. Karakteristik Citra Satelit. Universitas Sumatra Utara - Medan

Sitanggang, G. 2007. Karakteristik Satelit Penginderaan Jauh ALOS Untuk Misi Pemetaan Dan Potensi Data Untuk Aplikasi Pemetaan.Peneliti Pusat Pengembangan
Pemanfaatan dan Teknologi Penginderaan Jauh, LAPAN

Somantri, L. 2008. Penginderaan jauh lembang. Pendidkan Ilmu Pengetahuan Sosial UPI

Viesssman, W. Jr. dkk. 1977. Introduction to hydrology. New York Hagerstown Philadelphia San Fransisco London: HARPER \& ROW, PUBLISHERS

. 2007. "Penyusunan Rencana Detil Penanganan Banjir di Wilayah JABODETABEKJUR" BPDAS CitarumCiliwung. 